\title{
Ultrasonic and structural features of some borosilicate glasses modified with heavy metals
}

\author{
YASSER B SADDEEK \\ Department of Physics, Faculty of Science, Al-Azhar University, Assiut 71524, Egypt \\ ysaddeek@gmail.com
}

MS received 30 April 2016; accepted 14 September 2016; published online 9 June 2017

\begin{abstract}
A quaternary glass system $\mathrm{Na}_{1.4} \mathrm{~B}_{2.8} \mathrm{Si}_{x} \mathrm{~Pb}_{0.3-x} \mathrm{O}_{5.2+x}$, with $0 \leq x \leq 0.3$, was prepared and studied by Fourier transform infrared spectroscopy, density and ultrasonic techniques to debate the issue of the role of $\mathrm{SiO}_{2}$ in the structure of lead alkali borate glasses. The results indicate that $\mathrm{SiO}_{2}$ generates an abundance of bridging oxygen atoms, $\left[\mathrm{BO}_{4}\right]$ and $\left[\mathrm{SiO}_{4}\right]$ structural units and changes the bonds $\mathrm{B}-\mathrm{O}-\mathrm{B}$ and $\mathrm{Pb}-\mathrm{O}-\mathrm{B}$ to $\mathrm{Si}-\mathrm{O}-\mathrm{Si}$ and $\mathrm{B}-\mathrm{O}-\mathrm{Si}$. The latter bonds have higher bond strength and higher average force constant than the former bonds. Therefore, the glass structure becomes contracted and compacted, which decreases its molar volume and increases its rigidity. This concept was asserted from the increase in the ultrasonic velocity, Debye temperature and elastic moduli with the increase of $\mathrm{SiO}_{2}$ content. The present compositional dependence of the elastic moduli was interpreted in terms of the electron-phonon anharmonic interactions and the polarization of $\mathrm{Si}^{4+}$ cation. A good correlation was observed between the experimentally determined elastic moduli and those computed according to the Makishima-Mackenzie model.
\end{abstract}

Keywords. Alkali borate glasses; borosilicate glasses; elastic moduli; FTIR analysis.

\section{Introduction}

The structure of lead sodium borate glasses has received considerable attention due to its peculiarities [1,2]. These glasses have wide technological and industrial advantages when used in the fields of electronics [3], optical lenses with high refractive indices and low dispersion characteristics [4], transparent nuclear radiation shielding windows [5], solar energy technologies [6] and acoustic-optic devices [7,8].

According to extensive studies using several techniques, such as Fourier transform infrared spectroscopy (FTIR) [9], ultraviolet-visible spectroscopy [10], X-ray diffraction [11], $\mathrm{B}^{11}$ and $\mathrm{Pb}^{207}$ nuclear magnetic resonance spectroscopy [1113] and Raman spectroscopy [14,15], the structural and physical properties of these glasses revealed a wide composition range of $20-80 \mathrm{~mol} \% \mathrm{PbO}$ [16]. According to its concentration, $\mathrm{PbO}$ can enter the network of sodium borate glass as a network modifier or as a network former $[17,18]$. At lower concentrations, $\mathrm{PbO}$ modifies the network by forming $\mathrm{BO}_{4}$ tetrahedra at the rate of two $\mathrm{BO}_{4}$ groups per $\mathrm{PbO}$ molecule [19]; however, at higher concentrations, $\mathrm{PbO}$ can partly play the role of a glass-forming oxide in the form of $\mathrm{PbO}_{4}$ pyramids, with $\mathrm{Pb}^{2+}$ at the apex of the pyramid [20].

Several studies [21-25] have reported the variations in the $\mathrm{N}_{4}$ ratio (ratio of the concentration of $\mathrm{BO}_{4}$ to the concentrations of different borate structural units of the network) upon addition of the network former $\mathrm{SiO}_{2}$ to the network of lead borate-based glasses. The studies using moderate concentrations of $\mathrm{PbO}$ showed that $\mathrm{SiO}_{4}$ tetrahedra were tied to the sequences with their apexes and, in such cases, the $\mathrm{PbO}$ entered the glass network as a glass modifier by forming $\left[\mathrm{PbO}_{6}\right]$ pyramids [26].

The importance of these glasses was shown from their widespread applications in several scientific and industrial fields [27-30], and they have been noted to play a particular role in several technique-oriented glass applications, such as in the field of pharmacy [31], and in the manufacture of luminescent materials [32] and radiation shields [33]. Although the structure of binary or ternary lead borate or lead silicate-based glass systems has been extensively studied, there are few reports in the literature on the structural and mechanical properties of alkali lead borosilicate glasses. In the present study, an attempt has been made to follow a previous study [16] and undertake the structural and mechanical investigations of $\mathrm{Na}_{2} \mathrm{O}-\mathrm{PbO}-\mathrm{B}_{2} \mathrm{O}_{3}-\mathrm{SiO}_{2}$ glasses with the help of FTIR spectroscopy, density and molar volume, and ultrasonic techniques.

\section{Experimental}

\subsection{Synthesis of alkali lead borosilicate glasses}

The quaternary $\mathrm{Na}_{1.4} \mathrm{~B}_{2.8} \mathrm{Si}_{x} \mathrm{~Pb}_{0.3-x} \mathrm{O}_{5.2+x}(0 \leq x \leq 0.3)$ glass system was prepared using analytical reagent-grade $\mathrm{PbO}$, $\mathrm{Na}_{2} \mathrm{CO}_{3}, \mathrm{SiO}_{2}$ and $\mathrm{H}_{3} \mathrm{BO}_{3}$. A measure of $20 \mathrm{~g}$ of the starting materials was melted in a clean and dry porcelain crucible 
at approximately $1100^{\circ} \mathrm{C}$ for $60 \mathrm{~min}$ in an electrically heated $\mathrm{SiC}$ furnace at ordinary atmosphere. The melts were shaken during preparation to ensure homogeneity. The resulting melt was poured into preheated moulds kept at $250^{\circ} \mathrm{C}$. The prepared glass samples were subjected to annealing at $350^{\circ} \mathrm{C}$ for $1 \mathrm{~h}$, and then the furnace was left to cool to room temperature. The two opposite sides of the prepared samples were polished in order to carryout ultrasonic velocity measurements. The deviation in the parallelism of the two opposite side faces was about $\pm 8 \mu \mathrm{m}$. The weight losses were found to be less than $0.5 \%$.

\subsection{Structural and physical properties}

A Philips X-ray diffractometer (PW/1710) with Ni-filter, $\mathrm{Cu}-\mathrm{K}_{\alpha}$ radiation $(\lambda=1.542 \AA)$ powered at $40 \mathrm{kV}$ and $30 \mathrm{~mA}$ was used to confirm the amorphous nature of the prepared glasses. The patterns, as shown in figure 1, revealed the characteristic broad humps of the amorphous materials.

The FTIR absorption spectroscopy is a non-destructive tool. It can be used for resolving the characteristic broad bands of the borate glass network to obtain crucial information about the fundamental vibrations of the structural units of the studied glasses. The spectra of the studied glass samples in the wavenumber range of $400-4000 \mathrm{~cm}^{-1}$ with a resolution of $4 \mathrm{~cm}^{-1}$ were measured at room temperature by an infrared spectrophotometer (JASCO, FT/IR-430, Japan) using the $\mathrm{KBr}$ pellet technique. The spectra were corrected for dark current noises using a two-point baseline correction and normalized to eliminate the concentration effect of the powder sample in the $\mathrm{KBr}$ disc by making absorption of any spectrum varies from zero to one arbitrary unit.

The density $(\rho)$ of the prepared samples was determined using Archimedes's technique, in which toluene was the immersion fluid and the accuracy of the measurements was about $\pm 25 \mathrm{~kg} \mathrm{~m}^{-3}$. The molar volume $\left(V_{\mathrm{m}}\right)$ and the packing density $\left(V_{\mathrm{t}}\right)$ were determined as $M / \rho$ and $V_{\mathrm{t}}=\frac{1}{V_{\mathrm{m}}} \sum_{i} V_{i} x_{i}$;
$V_{i}=(4 \pi / 3) N_{A}\left[M R_{\mathrm{A}}^{3}+n R_{\mathrm{O}}^{3}\right]$, where $M$ is the molar weight of the glass calculated by multiplying $x$ times the molecular weights of the various constituents, $V_{i}$ is the packing factor and both $R_{\mathrm{A}}$ and $R_{\mathrm{O}}$ are the Pauling radii $(\AA)$ of oxide $\mathrm{A}_{m} \mathrm{O}_{n}$ [34,35].

The ultrasonic velocities [longitudinal $\left(v_{L}\right)$ and shear $\left(v_{T}\right)$ ] at room temperature were measured with uncertainty at 15 and $10 \mathrm{~m} \mathrm{~s}^{-1}$, respectively, using X-cut and Y-cut transducers (KARL DEUTSCH) operated at a fundamental frequency of $4 \mathrm{MHz}$ and a digital ultrasonic flaw detector (KARL DEUTSCH, Echograph model 1085). The two velocities besides the density were utilized in determining the longitudinal $(L)$ and shear $(G)$ moduli. For pure longitudinal waves, $L=\rho v_{L}^{2}$, and for pure transverse waves, $G=\rho v_{T}^{2}$. The elastic bulk modulus $\left(K_{\mathrm{e}}\right)$, Young's modulus $(Y)$ and Debye temperature $\left(\theta_{\mathrm{D}}\right)$ were determined from $L$ and $G$ using the standard relations adopted in a previous study [16]. The uncertainty in the elastic moduli is $\pm 0.15 \mathrm{GPa}$.

\section{Results and discussion}

\subsection{Infrared spectral studies}

The FTIR absorption spectra of the studied glasses, as shown in figure 2, represent the fingerprint broad bands of borate networks. The active absorption bands shown in figure 2 can be differentiated into four main regions in the ranges 3800 2200, 1640-1200, 1200-800 and 800-400 $\mathrm{cm}^{-1}$.

The changes in the broad bands of FTIR spectra of the glass network can be attributed to the structural grouping rearrangements as a function of $\mathrm{SiO}_{2}$ content. The observed broadness of the bands may be due to the overlapping of particular bands with each other. Each specific band has a centre $(C)$, which is related to the vibration of a specific structural group, and a relative area $(A)$, which is proportional to the concentration of this structural unit. A de-convolution process, as described

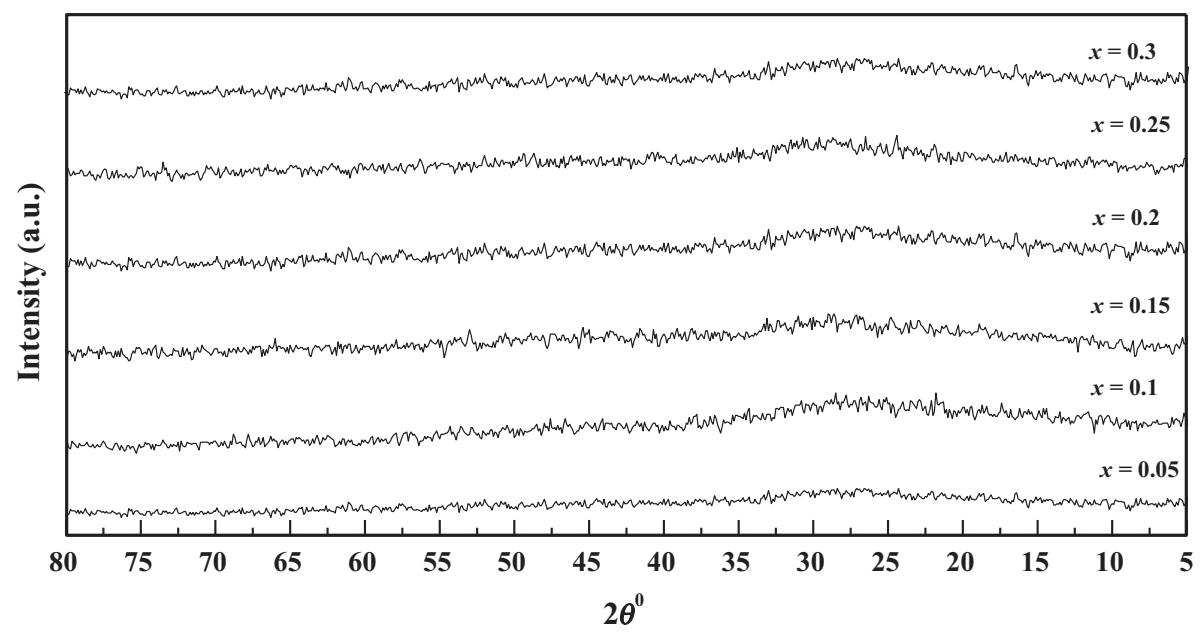

Figure 1. X-ray diffraction spectra of $\mathrm{Na}_{1.4} \mathrm{~B}_{2.8} \mathrm{Si}_{x} \mathrm{~Pb}_{0.3-x} \mathrm{O}_{5.2+x}$ glasses. 


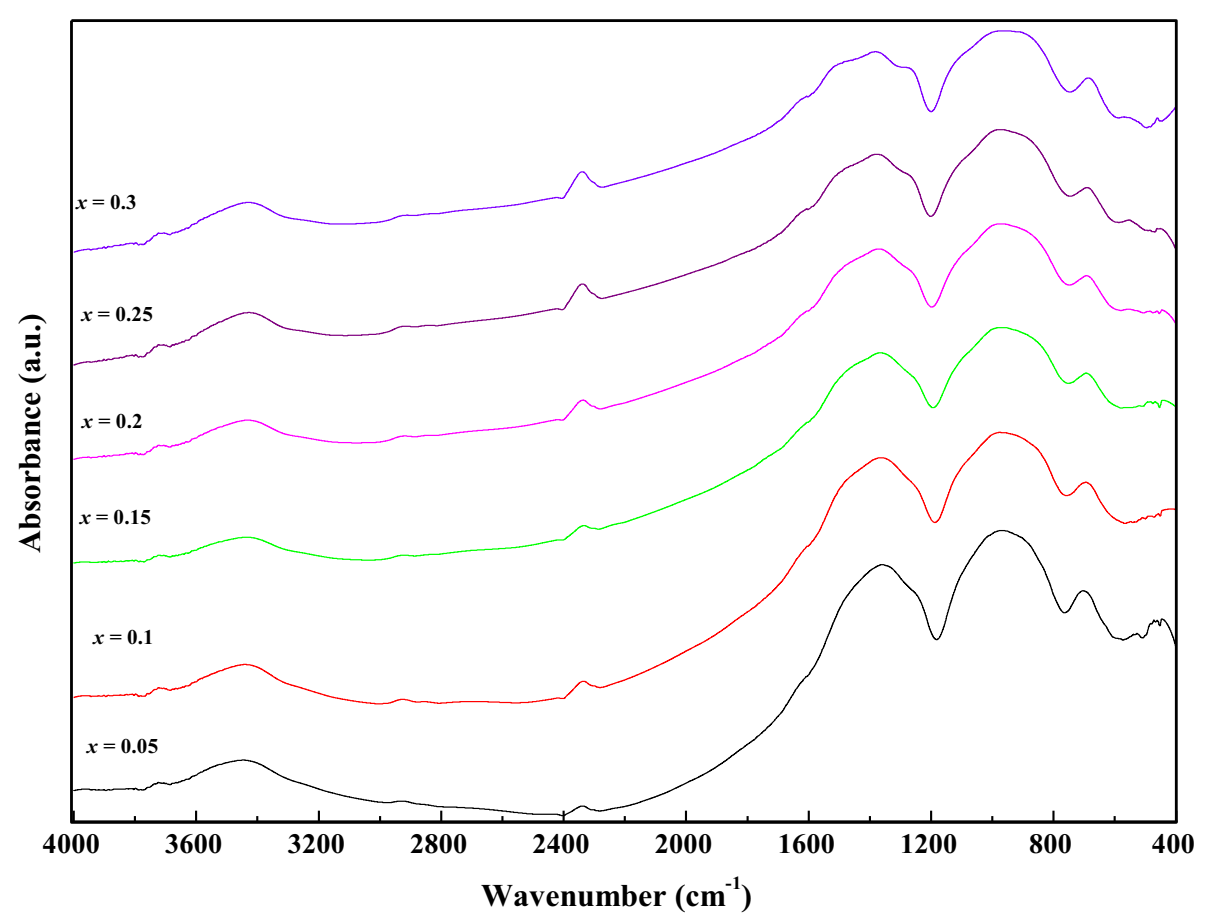

Figure 2. Infrared absorption spectra of $\mathrm{Na}_{1.4} \mathrm{~B}_{2.8} \mathrm{Si}_{x} \mathrm{~Pb}_{0.3-x} \mathrm{O}_{5.2+x}$ glasses.

Table 1. The curve fitting parameters (the band centre $C$ and the relative area $A$ ) for the glass system $\mathrm{Na}_{1.4} \mathrm{~B}_{2.8} \mathrm{Si}_{x} \mathrm{~Pb}_{0.3-x} \mathrm{O}_{5.2+x}$, with $0 \leq x \leq 0.3$.

\begin{tabular}{|c|c|c|c|c|c|c|c|c|c|c|c|c|c|}
\hline \multirow[t]{2}{*}{0.05} & Centre & 452 & 542 & 641 & 709 & 823 & 900 & 987 & 1086 & 1243 & 1340 & 1464 & - \\
\hline & R. area & 4.7 & 1.8 & 4.1 & 7.3 & 8.6 & 12.6 & 15.6 & 14.1 & 3.4 & 18.3 & 9.5 & - \\
\hline \multirow[t]{2}{*}{0.1} & Centre & 424 & 495 & 639 & 701 & 828 & 919 & 1030 & 1125 & 1243 & 1347 & 1487 & - \\
\hline & R. area & 3 & 2 & 7.5 & 6.8 & 10 & 15.9 & 19.5 & 4.4 & 2.4 & 20.3 & 8.2 & - \\
\hline \multirow[t]{2}{*}{0.15} & Centre & 424 & 466 & 651 & 690 & 835 & 907 & 1027 & 1128 & 1247 & 1339 & 1484 & - \\
\hline & R. area & 0.8 & 2.9 & 7.7 & 6 & 10 & 17.2 & 19.6 & 4.2 & 1.6 & 18.7 & 11.3 & - \\
\hline \multirow[t]{2}{*}{0.2} & Centre & 427 & 561 & 658 & 707 & 819 & 912 & 1030 & 1127 & 1267 & 1371 & 1483 & - \\
\hline & R. area & 0.8 & 6.6 & 7.6 & 4.9 & 8.8 & 16 & 19 & 6.9 & 2.2 & 16.5 & 10.7 & - \\
\hline \multirow[t]{2}{*}{0.25} & Centre & - & 555 & 664 & 719 & 830 & 924 & 1035 & 1140 & 1254 & 1343 & 1487 & 1638 \\
\hline & $\mathrm{R}$. area & - & 6.9 & 7.8 & 4.4 & 9 & 16.2 & 19 & 7 & 1.7 & 14.9 & 11.1 & 2 \\
\hline \multirow[t]{2}{*}{0.3} & Centre & - & 556 & 671 & 690 & 822 & 912 & 1038 & 1136 & 1261 & 1369 & 1514 & 1636 \\
\hline & R. area & - & 1 & 8.9 & 3.1 & 11.4 & 17.8 & 21.3 & 6.2 & 3.6 & 13.6 & 10.1 & 3 \\
\hline
\end{tabular}

elsewhere [21], should be performed to get such parameters. The de-convolution parameters of the bands for the investigated glasses are given in table 1. Figures 3 and 4 illustrate the de-convolution spectra of the samples with $x=0$ and 0.3 , respectively, and the difference between the experimental and simulated curves. The assignments of the resulted structural units help in the calculation of the fraction of the four coordinated boron atoms, $\mathrm{N}_{4}$.

The wide bands ranging from 3800 to $2400 \mathrm{~cm}^{-1}$ are attributed to water groups, while the weak band at $\sim 2340 \mathrm{~cm}^{-1}$ is attributed to hydrogen bonding [17].
The band at $\sim 1480 \mathrm{~cm}^{-1}$ can be attributed to vibrations of $\mathrm{BO}_{3}$ and $\mathrm{BO}_{2} \mathrm{O}^{-}$borate structural units; the band groups at $\sim 1350 \mathrm{~cm}^{-1}$ can be attributed to stretching vibrations of the $\mathrm{B}-\mathrm{O}$ of trigonal $\left(\mathrm{BO}_{3}\right)^{3-}$ units in metaborates, pyroborates and orthoborates; and the bands at $\sim 1250 \mathrm{~cm}^{-1}$ can be attributed to stretching vibrations of the $\mathrm{B}-\mathrm{O}$ of $\left(\mathrm{BO}_{3}\right)^{3-}$ unit involving mainly the linkage oxygen [36].

The bands at $1086-1140 \mathrm{~cm}^{-1}$ are attributed to the B-O-B linkage (diborate linkage), in which both boron atoms are tetrahedrally coordinated, and to the triborate super structural units [17]. The absorption region at $\sim 987-1038 \mathrm{~cm}^{-1}$ is 


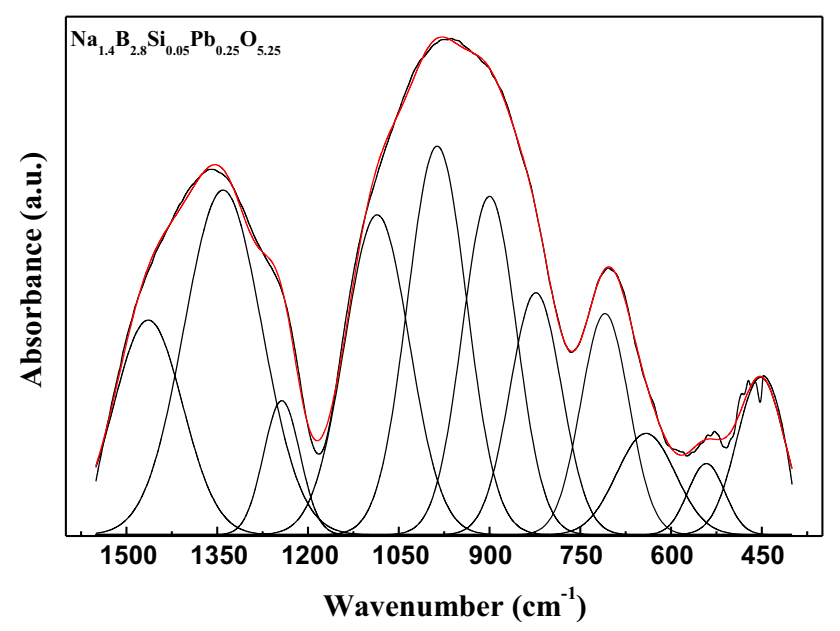

Figure 3. Band de-convolution of infrared spectrum for $\mathrm{Na}_{1.4} \mathrm{~B}_{2.8}$ $\mathrm{Si}_{0.05} \mathrm{~Pb}_{0.25} \mathrm{O}_{5.25}$ glass.

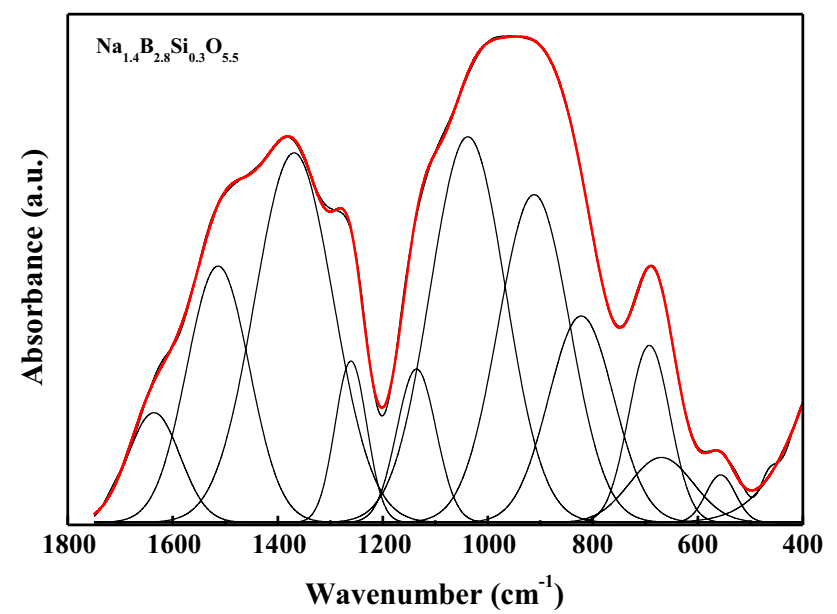

Figure 4. Band de-convolution of infrared spectrum for $\mathrm{Na}_{1.4} \mathrm{~B}_{2.8}$ $\mathrm{Si}_{0.3} \mathrm{O}_{5.5}$ glass.

attributed to the asymmetrical stretching vibrations of $\mathrm{Si}-\mathrm{O}-$ $\mathrm{Si}$ of $\left[\mathrm{SiO}_{4}\right]$ structural unit, and the bands at $\sim 819-835 \mathrm{~cm}^{-1}$ can be attributed to the stretching vibrations of tetrahedral $\mathrm{BO}_{4}$ units [36].

The weak bands at $\sim 415-427 \mathrm{~cm}^{-1}$ and at $\sim 542-561 \mathrm{~cm}^{-1}$ are attributed to vibrations of $\left[\mathrm{PbO}_{6}\right]$ structural units and to asymmetric vibration of $\mathrm{B}-\mathrm{O}-\mathrm{Si}$ units, respectively. The bands at $\sim 609-664 \mathrm{~cm}^{-1}$ and at $\sim 690-717 \mathrm{~cm}^{-1}$ are attributed to bending vibrations of $\mathrm{Si}-\mathrm{O}-\mathrm{Si}$ linkages and to bond bending vibrations of $\mathrm{B}-\mathrm{O}-\mathrm{B}$ linkages of the boron-oxygen network, respectively $[9,21,36]$.

It was stated that, the bonding of $\mathrm{PbO}$ at low concentrations $(\leq 40 \mathrm{~mol} \%)$ with alkali borate glasses is strongly ionic and $\mathrm{Pb}^{2+}$ enters the network in an interstitial manner; every oxygen atom of $\mathrm{PbO}$ is used to convert two $\mathrm{BO}_{3}$ units to two $\mathrm{BO}_{4}$ units [16,37]. Furthermore, addition of $\mathrm{SiO}_{2}$ to borate-based glasses causes an increase in the fraction of $\mathrm{BO}_{4}$ tetrahedra and creates non-bridging oxygen $(\mathrm{NBO})$ atoms on the $\left[\mathrm{SiO}_{4}\right]$ silica tetrahedral [38].

Thus, the variation in the concentration of the $\mathrm{SiO}_{2}$ effectively changes the FTIR spectra, as discussed below.

The bands at $\sim 12043$ to $1638 \mathrm{~cm}^{-1}$ are sensitive to the gradual increase of $\mathrm{SiO}_{2}$ up to $x=0.2$ in the glass network. Their relative areas are decreased due to the deformation of various borate structural units. The deformation was incorporated in the disruption of the bonds connecting neighbouring $\left[\mathrm{NaO}_{6}\right],\left[\mathrm{BO}_{3}\right]$ and $\left[\mathrm{PbO}_{6}\right]$ groups. This disruption strongly influences the local fields in the glass network and causes a modification in the electron distribution of the $\mathrm{B}-\mathrm{O}-\mathrm{B}$ and $\mathrm{Pb}-\mathrm{O}-\mathrm{Pb}$ bonds. As a result, there will be abundance in the oxygen environment and hence an increase in the creation of bridging oxygen atoms in the network. These oxygen atoms increase the network connectivity, and the ring-type structure of the borate glass will be close packed through the polymerization of the matrix. Thus, formation of $\left[\mathrm{BO}_{4}\right]$ and $\left[\mathrm{SiO}_{4}\right]$ structural units is expected. This observation was raised from the following:

(i) The decrease in the relative area of both the characteristic band of $\mathrm{PbO}_{6}$ and that of the bending vibrations of $\left[\mathrm{BO}_{3}\right]$ on one hand; and

(ii) The increase in the relative area of $\mathrm{B}-\mathrm{O}-\mathrm{Si}$ units, the bending vibrations of $\mathrm{Si}-\mathrm{O}-\mathrm{Si}$ linkages, $\mathrm{N}_{4}$ (table 2) and the relative area of the absorption bands in the region $800-1200 \mathrm{~cm}^{-1}$ on the other.

This is correlated with an increase in the ratio of oxygen to boron atoms $(O / B)$ (table 2), the substitution of low bond strength $\mathrm{Pb}-\mathrm{O}$ by high bond strength $\mathrm{Si}-\mathrm{O}[39,40]$ and the change from the continuous $\mathrm{Pb}-\mathrm{O}-\mathrm{B}$ and $\mathrm{B}-\mathrm{O}-$ $\mathrm{B}$ networks to the continuous $\mathrm{B}-\mathrm{O}-\mathrm{Si}$ and $\mathrm{Si}-\mathrm{O}-\mathrm{Si}$ networks. Therefore, this type of glasses can be considered to be formed from two effective glass formers, namely $\mathrm{SiO}_{2}$ and $\mathrm{B}_{2} \mathrm{O}_{3}$, with $\left[\mathrm{BO}_{3}\right],\left[\mathrm{BO}_{4}\right]$ and $\left[\mathrm{SiO}_{4}\right]$ structural units connected with each other to form stable structural groups.

Bands located at $\sim 1638 \mathrm{~cm}^{-1}$ appear when there is a progressive increase of $\mathrm{SiO}_{2}$ beyond $x=0.2$ in the glass network. This band is attributed to anti-symmetrical stretching vibrations with three NBOs of $\mathrm{B}-\mathrm{O}-\mathrm{B}$ groups. In this case, the alkali $\mathrm{Na}^{+}$will favour bonding to silicon than to boron and new $\mathrm{Si}-\mathrm{O}-\mathrm{Na}$ bonds are formed. Due to the smaller area of these bands, the new bonds create NBOs and decrease the connectivity of borosilicate network to some extent.

\subsection{Density and molar volume}

The values of the density and the molar volume are listed in table 2. The results of the density and the molar volume, as shown in figure 5 , revealed that the density and the molar volume of the glass samples decreased with the increase in $\mathrm{SiO}_{2}$ 
content. The density values of the studied glasses are greater than the density of the $\mathrm{Na}_{2} \mathrm{~B}_{4} \mathrm{O}_{7}$ glass and lower than that of the $\mathrm{Na}_{2} \mathrm{~B}_{4} \mathrm{O}_{7}-\mathrm{PbO}$ glass [16]. The decrease in density is attributed to the lower molecular mass of $\mathrm{SiO}_{2}$ (60.085) than that of $\mathrm{PbO}$ (223.199), which is the dominant factor affecting the change in density for all glass samples. The decrease in the density can also be related to the type of structural unit [41]. The density of the $\left[\mathrm{SiO}_{4}\right]$ and $\left[\mathrm{BO}_{4}\right]$ are larger than the density of $\left[\mathrm{BO}_{3}\right]$ and lower than the density of $\left[\mathrm{PbO}_{6}\right]$ structural units. Therefore, as the mole fractions of $\mathrm{SiO}_{2}$ increase, the structural units of borate and lead groups decrease, which decreases the density of the studied glasses.

The molar volume is defined as the volume occupied by one gram-molecule of the glass unit mass. The compositional dependence of the molar volume on $\mathrm{SiO}_{2}$ content can be explained taking into account the glass packing density. The glass packing density is defined as the ratio of the minimum theoretical volume occupied by the ions to the corresponding effective volume of the glass [42] (table 2). According to IR analysis, as the $\mathrm{SiO}_{2}$ content increases, the longer bond length $\mathrm{Pb}-\mathrm{O}$ will be replaced by the shorter bond length $\mathrm{Si}-\mathrm{O}$ and there will be plenty of bridging oxygen atoms that make the structure compact and tight [21]. It means that the voids in the network are able to accommodate $\mathrm{SiO}_{2}$ without any expansion of the glass matrix. Moreover, the compactness of the glasses is suggested to depend on the ionic radii or the packing factor of the constituents of the network. The packing factors of $\mathrm{SiO}_{2}, \mathrm{~B}_{2} \mathrm{O}_{3}, \mathrm{Na}_{2} \mathrm{O}$ and $\mathrm{PbO}$ are 14, 20.8, 11.2 and $11 \mathrm{~cm}^{3} \mathrm{~mol}^{-1}$, respectively [34]. Thus, the packing density of the glasses will increase with the increase in $\mathrm{SiO}_{2}$ content, which can lead to a decrease in the size of the interstices and in the molar volume.

\subsection{Ultrasonic and elastic moduli of glass}

The values of ultrasonic wave velocities $\left(v_{L}\right.$ and $\left.v_{S}\right)$ and elastic moduli (bulk modulus, $K_{\mathrm{e}}$, and Young's modulus, $E$ ) are listed in table 2 and the compositional dependence of longitudinal and transverse sound velocities on $\mathrm{SiO}_{2}$ content is shown in figure 6. It was deduced from the analysis of FTIR and density that $\mathrm{SiO}_{2}$ molecules enter interstitially in the lead alkali borate network and, therefore, a modification of the bonds and the structural units occur without the expansion of the glass matrix. As the $\mathrm{SiO}_{2}$ content increases, the number of bridging oxygen atoms, the number of tetrahedral structural units and the high bond strength $\mathrm{B}-\mathrm{O}-\mathrm{Si}$ bonds increase [21]. Consequently, the connectivity, compactness, polymerization and rigidity of the glass network also increase, which increases the ultrasonic wave velocities. These observations can be confirmed from the calculated number of bonds per unit volume $\left(n_{\mathrm{b}}\right)$. This parameter was computed taking into account $\mathrm{N}_{4}$, as described elsewhere [43], and its values are listed in table 2. It can be observed that the glass that has a higher velocity also has the higher number of bonds per unit volume. 


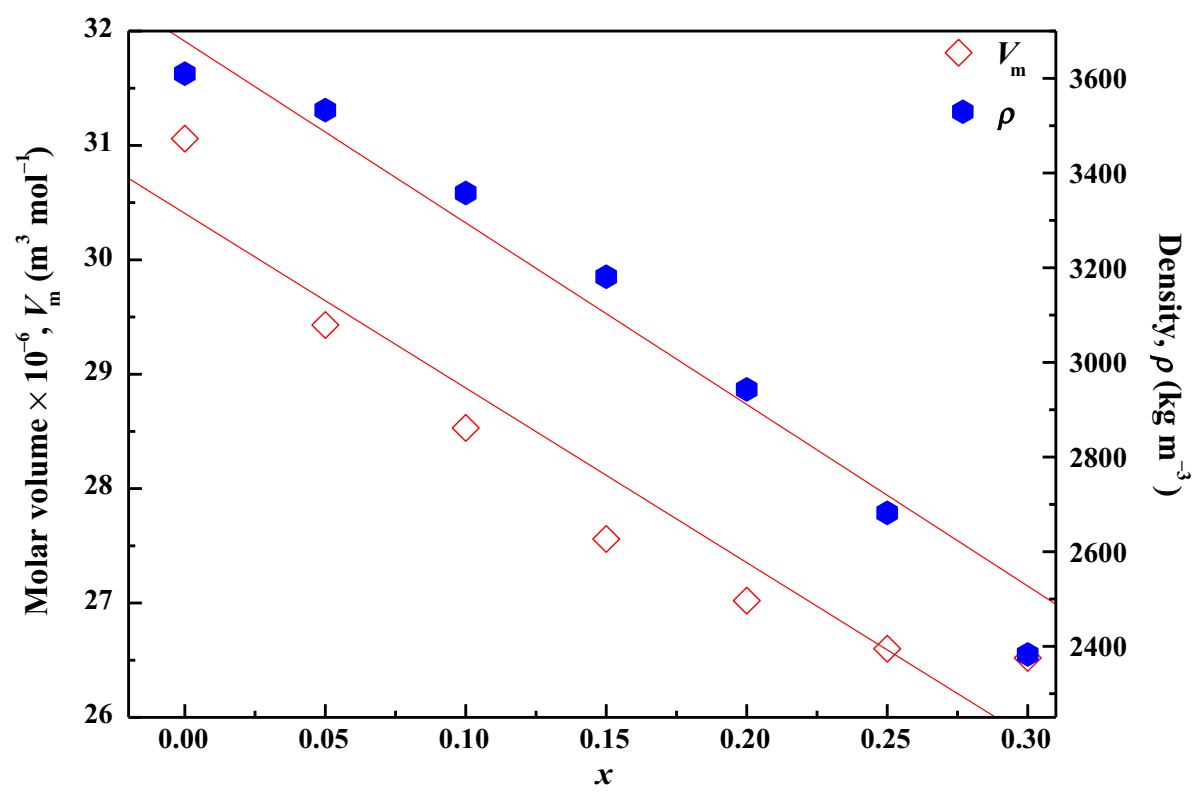

Figure 5. Dependence of the density and the molar volume of the quaternary glass system $\mathrm{Na}_{1.4} \mathrm{~B}_{2.8} \mathrm{Si}_{x} \mathrm{~Pb}_{0.3-x} \mathrm{O}_{5.2+x}$ on the parameter $x$ (the lines are drawn as a guide to the eye).

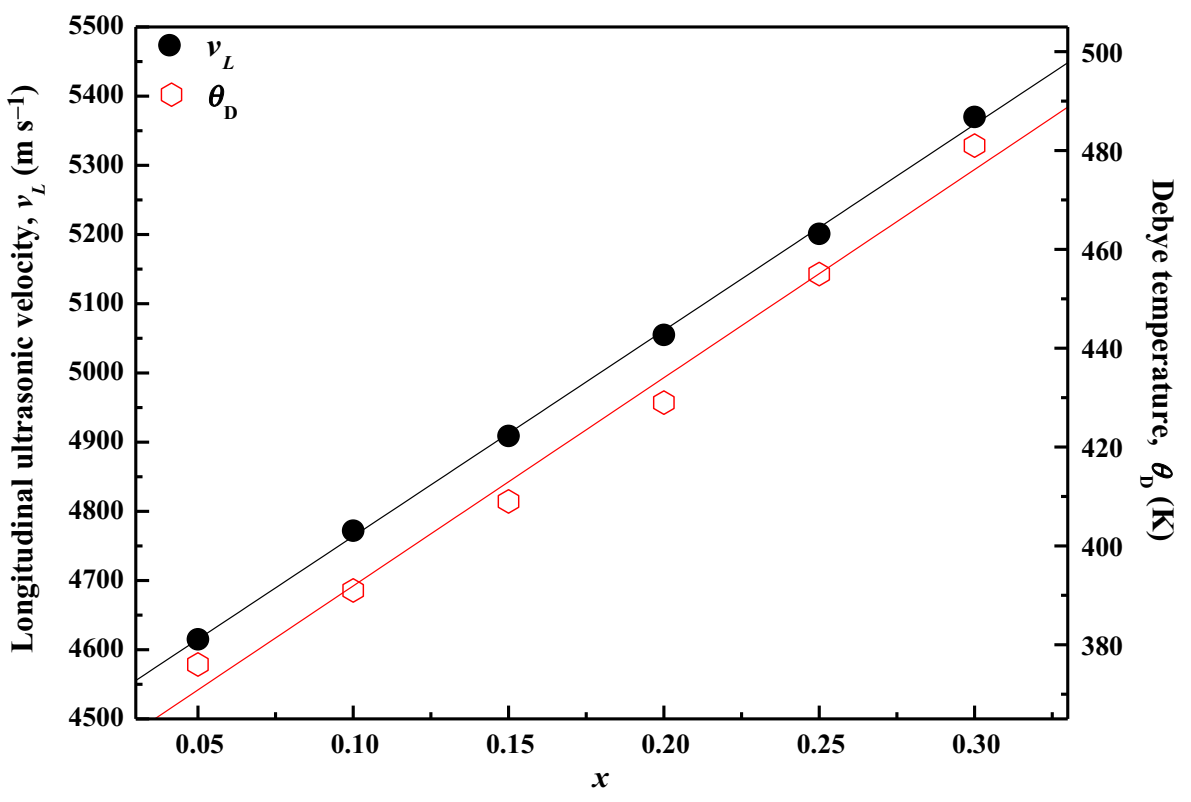

Figure 6. Compositional dependence of the longitudinal ultrasonic velocity and Debye temperature in the quaternary glass system $\mathrm{Na}_{1.4} \mathrm{~B}_{2.8} \mathrm{Si}_{x} \mathrm{~Pb}_{0.3-x} \mathrm{O}_{5.2+x}$ on the parameter $x$ (the lines are drawn as a guide to the eye).

Another important parameter that depends on both the mean ultrasonic velocity and the atomic vibration of the glass network is the Debye temperature $\left(\theta_{\mathrm{D}}\right)$. The values of Debye temperature $\left(\theta_{\mathrm{D}}\right)$ are listed in table 2 . The atomic vibration in its turn depends on the dimensionality of the glass network. The dimensionality, as discussed previously $[16,44]$, is defined in terms of the fractal bond connectivity, which is the ratio $d=4 G / K$. The value of $d$ is 3 for 3D networks of tetrahedral coordination polyhedra. The investigated glasses have values of $d$ ranging between 2.4 and 2.5, which implies that the networks of these glasses have 3D structures. However, pure $\mathrm{SiO}_{2}$ glass shows this value to be 3 . Thus, the increase in the mean values of ultrasonic velocity and Debye temperature is mainly due to the increase in bridging oxygen atoms. 


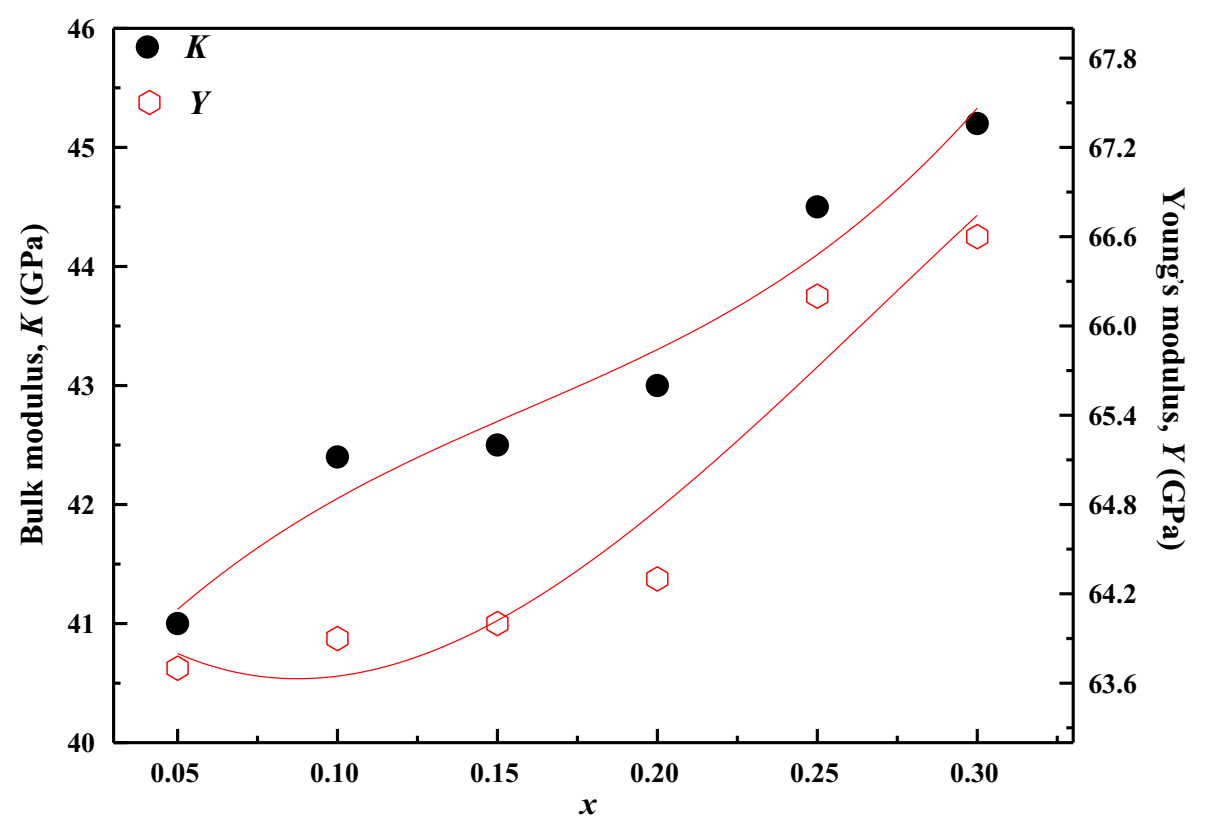

Figure 7. Compositional dependence of the elastic moduli (Young's and bulk moduli) in $\mathrm{Na}_{1.4} \mathrm{~B}_{2.8} \mathrm{Si}_{x} \mathrm{~Pb}_{0.3-x} \mathrm{O}_{5.2+x}$ glasses on the parameter $x$ (the lines are drawn as a guide to the eye).

As shown in table 2 and figure 7, the elastic moduli (bulk $(K)$ and Young's $(Y)$ moduli) values show an increase due to the $\mathrm{SiO}_{2}$ effect. In general, the elastic moduli are affected by the variations in the anharmonic properties and the density of the glass on one hand and the ultrasonic velocity on the other.

The anharmonic properties of the glass are the non-linearity of the atomic displacements. Therefore, as analysed before, as the $\mathrm{SiO}_{2}$ content increases, there will be an abundance of bridging oxygen atoms that decrease the molar volume and increase the compactness of the structure. As a result, the amplitude of the oxygen vibrations decrease, which results in the disappearance of relatively large electron-phonon anharmonic interactions. Oxygen was considered as it has a smaller mass than the masses of various cations of the studied glasses. The low vibrational anharmonicity of the acoustic modes of borate-based glasses can be attributed to the increase in $\left[\mathrm{BO}_{4}\right]$ and $\left[\mathrm{SiO}_{4}\right]$ structural units that cause the increase in the rigidity, which in turn increases the elastic moduli.

The second approach in explaining the variations in the elastic moduli is the dependence of the ultrasonic wave velocities on the average strength of the bond and the cross-link density. The cross-link density was computed as described elsewhere [43]. The average strength of the bond is related to the stretching force constant and to the inverse of the bond length between the atoms, while the cross-link density is controlled by the number of bridging oxygen atoms. As the average force constant increases, the energy required to produce a given degree of distortion of bond angle or length increases. The force constant on its turn is related to the cation field strength of the modifier. High field strength cations, such as $\mathrm{Si}^{+4}$, polarize their environment strongly, enhance the iondipole interaction and increase the packing density (table 2) due to the local contraction of the network around such a cation. Thus, the type of bonding and the coordination states of the various oxides incorporated in a glass network will control the elastic moduli of this structure. The bulk modulus of a covalent network is determined by the bond density (number of bonds in a unit volume) and by the stretching force constant, i.e., the bulk modulus is a measure of its resistance to uniform compression. Thus, the observed increase in the bulk modulus is associated with an increase in the number of bonds per unit glass formula unit.

Quantitative analysis of the experimental results of the elastic moduli is performed using the Makishima-Mackenzie model, which is based on the atomic packing density (ionic radii of the elements) and the bond strength (dissociation energy) of the oxides in the studied glass system [16,4547]. The details of the computation according to this model are described elsewhere [47]. The values of the elastic moduli according to this model, considering the influence of the structural units constituting the investigated glass structure, are given in table 2 . The values of the dissociation energy for $\mathrm{Na}_{2} \mathrm{O}, \mathrm{PbO}$ and $\mathrm{SiO}_{2}$ are $31.9 \times 10^{6}$, $25.3 \times 10^{6}$ and $68 \times 10^{6} \mathrm{~kJ} \mathrm{~m}^{-3}$, respectively [34]. The dissociation energy of $\mathrm{B}_{2} \mathrm{O}_{3}$ has two values, $16.4 \times 10^{6}$ (coordination number 3) and $77.9 \times 10^{6} \mathrm{~kJ} \mathrm{~m}^{-3}$ (coordination number 4).

The values of the experimentally determined elastic moduli, according to the model, are lower than those computed theoretically, which was ascribed to the increasing packing 


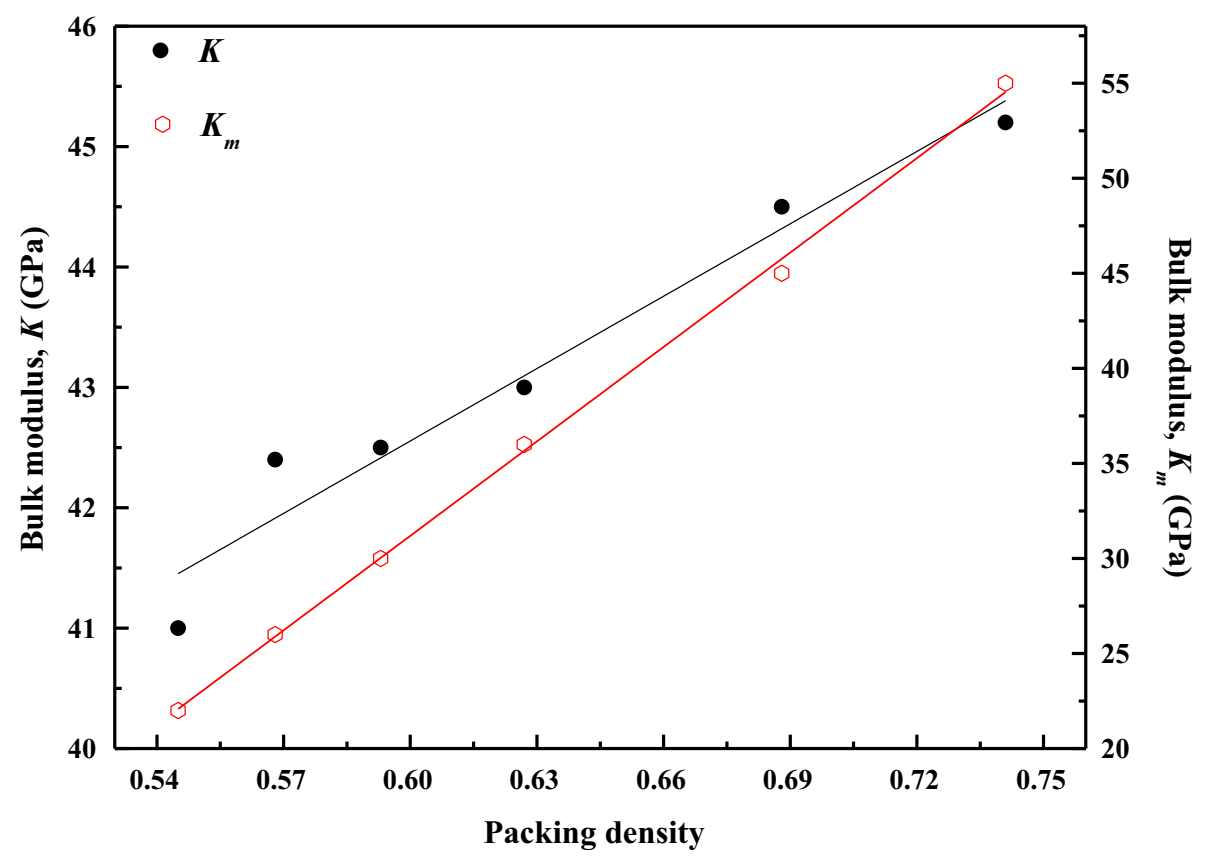

Figure 8. Variation of the experimental and theoretical bulk moduli values with the values of the packing density of the quaternary glass system $\mathrm{Na}_{1.4} \mathrm{~B}_{2.8} \mathrm{Si}_{x} \mathrm{~Pb}_{0.3-x} \mathrm{O}_{5.2+x}$ (the lines are drawn as a guide to the eye).

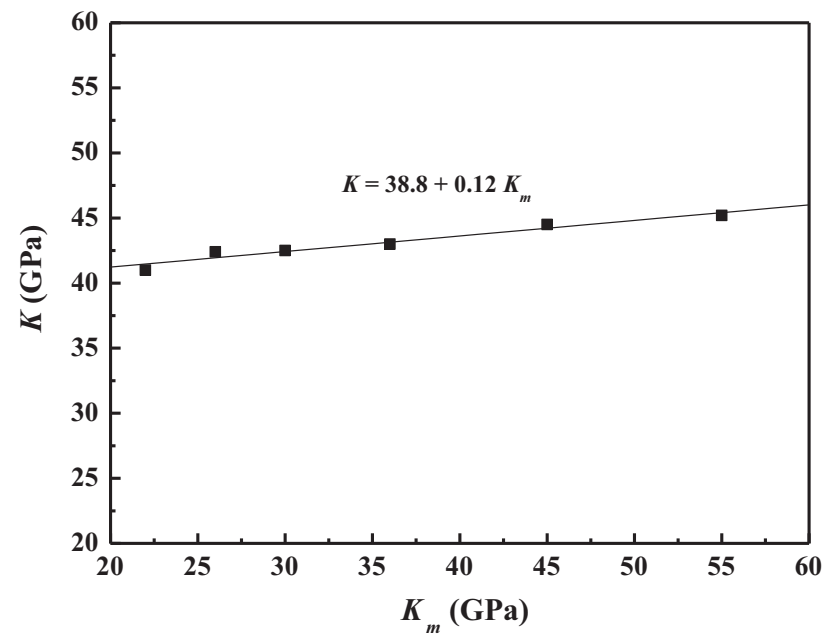

Figure 9. Relationship between the experimental and theoretically calculated values of bulk modulus of the quaternary glass system $\mathrm{Na}_{1.4} \mathrm{~B}_{2.8} \mathrm{Si}_{x} \mathrm{~Pb}_{0.3-x} \mathrm{O}_{5.2+x}$ (the line is drawn as a guide to the eye).

density and the dissociation energy on one hand and the decreasing molar volume and the density on the other, as shown in figure 8. Thus, addition of $\mathrm{SiO}_{2}$ will increase the packing density and the dissociation energy per unit volume of the system, and this in turn increases their rigidity and elastic moduli.

The changes in the elastic moduli, according to this model, confirm the changes in the experimentally determined elastic moduli of the tightly packed glasses, and these changes are in good agreement with the increase in the stretching force constant of the studied glasses. Figure 9 shows the satisfactory agreement between the computed and the experimental bulk modulus, with a correlation ratio of $97 \%$. These results confirm that this model is valid for the prediction of the elastic moduli of borosilicate glasses. The study of elastic or ultrasonic properties of the glasses helps in estimating their mechanical strength.

\section{Conclusion}

Structural and mechanical studies on quaternary $\mathrm{Na}_{1.4}$ $\mathrm{B}_{2.8} \mathrm{Si}_{x} \mathrm{~Pb}_{0.3-x} \mathrm{O}_{5.2+x}(0 \leq x \leq 0.3)$ glass system have been performed. The addition of $\mathrm{SiO}_{2}$ interstitially in the lead alkali borate network degenerates the network, and the concentration of $\mathrm{Na}^{+}$and $\mathrm{Pb}^{2+}$ ions are changed. Bridging oxygen atoms, $\left[\mathrm{SiO}_{4}\right]$ and $\left[\mathrm{BO}_{4}\right]$ structural units and new $\mathrm{Si}-\mathrm{O}-\mathrm{Si}$ and $\mathrm{B}-\mathrm{O}-\mathrm{Si}$ networks are created. These bonds have high bond strength and high stretching force constant. The overall molar volume and the density of the glass system decrease as the $\mathrm{SiO}_{2}$ content increases, which increases the packing density and the dissociation energy of the network. Accordingly, the rigidity of the network increases, which increases the ultrasonic velocity and Debye temperature. The elastic moduli of borosilicate glasses are controlled by the type of bonding and the creation of $\left[\mathrm{BO}_{4}\right]$ and $\left[\mathrm{SiO}_{4}\right]$ structural units. The elastic moduli values were found to increase, and this increase was 
confirmed based on the increase in the elastic moduli value according to the Makishima-Mackenzie model.

\section{References}

[1] Dimitriv V V, Kim S H, Yoko T and Sakka S 1993 J. Ceram. Soc. Jpn. 10159

[2] Kamitsos E I and Kasakassides M A 1989 Phys. Chem. Glasses 3019

[3] Edelman I S, Ivanova O S, Petrakovskaja E A, Velikanov D A, Tarasov I A, Zubavichus Y V et al 2015 J. Alloys Compd. 624 60

[4] Pisarska J, Lisiecki R, Ryba-Romanowski W, Dominiak-Dzik G, Goryczka T, Grobelny Ł et al 2011 J. Non-Cryst. Solids 357 1228

[5] Sears V F 1992 Neutrons News 326

[6] Marzouk M A, Ibrahim S and Hamd Y M 2014 J. Mol. Struct. 1076576

[7] Rajaramakrishna R, Saiyasombat C, Anavekar R V and Jain H 2014 J. Non-Cryst. Solids 406107

[8] El-Diasty F, Moustafa F A, Abdel-Wahab F A, Abdel-Baki M and Fayad A M 2014 J. Alloys Compd. 605157

[9] Saddeek Y, Mohamed G, Shokry H, Mostafa A and Abd Elfadeel G 2015 J. Non-Cryst. Solids 419110

[10] Farouk M, Abd El-Maboud A, Ibrahim M, Ratep A and Kashif I 2015 Spectrochim. Acta A149 338

[11] Takaishi T, Jin J, Uchino T and Yoko T $2000 \mathrm{~J}$. Am. Ceram. Soc. $\mathbf{8 3} 2543$

[12] Fayon F, Bessada C, Massiot D, Farnan I and Coutures J P 1998 J. Non-Cryst. Solids 232-234 403

[13] Yoko T, Tadanaga K, Miyaji F and Sakka S 1992 J. Non-Cryst. Solids 150192

[14] Meera B N, Sood A K, Chandrabhas N and Ramakrishna J 1990 J. Non-Cryst. Solids 126224

[15] Lucacel R C and Ardelean I 2007 J. Non-Cryst. Solids 353 2020

[16] Saddeek Y 2009 J. Alloys Compd. 46714

[17] Singh D, Singh K, Singh G, Mohan S, Arora M and Sharma G 2008 J. Phys. Condens. Matter 20075228

[18] Worrell C A and Henshall J 1978 J. Non-Cryst. Solids 29283

[19] Doweidar H and Saddeek Y 2010 J. Non-Cryst. Solids 356 1452

[20] Fayon F, Landron C, Sakurai K, Bessada C and Massiot D 1999 J. Non-Cryst. Solids 24339

[21] Saddeek Y, Gaafar M and Bashier S 2010 J. Non-Cryst. Solids 3561089

[22] Saini A, Khanna A, Michaelis V, Kroeker S, Gonzalez F and Hernandez D 2009 J. Non-Cryst. Solids 3552323
[23] El-Damrawi G, Muller-Warmuth W, Doweidar H and Gohar I A 1992 J. Non-Cryst. Solids 146137

[24] Wood J, Prabakar S, Mueller K and Pantano C 2004 J. NonCryst. Solids 349276

[25] McKeown D, Gan H and Pegg I 2005 J. Non-Cryst. Solids 351 3826

[26] Witkowska A, Rybicki J and Cicco A 2005 J. Non-Cryst. Solids 351380

[27] Manara D, Grandjean A and Neuville D R 2009 Am. Min. 94 777

[28] El-Alaily N and Mohamed R 2003 Mater. Sci. Eng. B 98 193

[29] Rajendran V, Palanivelu N, El-Batal H A, Khalifa F A and Shaft N A 1999 Acoust. Lett. 23113

[30] Hirashima H, Arari D and Yoshida T 1985 J. Am. Ceram. Soc. 68486

[31] Wananuruksawong $\mathrm{R}$, Jinawath $\mathrm{S}$, Padipatvuthikul $\mathrm{P}$ and Wasanapiarnpong T 2011 IOP Conf. Ser. Mater. Sci. Eng. 18 192010

[32] Wen H and Tanner P 2015 J. Alloys Compd. 625328

[33] Yang J K, Wang T S, Zhang G F, Peng H B, Chen L, Zhang M L et al 2013 Nucl. Instrum. Methods Phys. Res. B 307 541

[34] Inaba S, Fujino S and Morinaga K 1999 J. Am. Ceram. Soc. 82 3501

[35] Makishima A and Mackenzie J D 1973 J. Non-Cryst. Solids 12 35

[36] Rao T G V M, Rupesh Kumar A, Neeraja K, Veeraiah N and Rami Reddy M 2014 Spectrochim. Acta A 118744

[37] Baccaro S, Sharma G, Thind K S, Singh D and Cecillia A 2007 Nucl. Instrum. Methods Phys. Res. B 260613

[38] Kaur R, Singh S and Pandey O P 2014 J. Mol. Struct. 1060 251

[39] Lide D 2004 CRC handbook of chemistry and physics 84th edn (Boca Raton, Fl: CRC Press)

[40] Wells A 1975 Structural inorganic chemistry 4th edn (Oxford: Clarendon Press)

[41] Doweidar H, El-egili K and Abd El-Maksoud S 2000 J. Phys. D: Appl. Phys. 332532

[42] Bootjomchai C, Laopaiboon R, Pencharee S and Laopaiboon J 2014 J. Non-Cryst. Solids 38837

[43] Saddeek Y 2004 Physica B 344163

[44] Hwa L G, Chao W C and Szu S P 2002 J. Mater. Sci. 373423

[45] Makishima A and Mackenzie J 1975 J. Non-Cryst. Solids 17 147

[46] Rocherulle J, Ecolivet C, Poulain M, Verdier P and Laurent Y 1989 J. Non-Cryst. Solids 108187

[47] Saddeek Y B, Kaid M A and Ebeid M R 2014 J. Non-Cryst. Solids 38730 